\title{
L-carnitine acts as a neuroprotecor against aspartame injury in Wistar albino rat
}

\author{
Reham Z. Hamza ${ }^{1,2}$, Rasha A. Al-Eisa ${ }^{1}$ and Nahla S. El-Shenawy ${ }^{3 *}$
}

\begin{abstract}
Background: $L$-carnitine (LC) plays an important role in the oxidative/antioxidative balance of different organs. The study has explored the effect of the daily administration of aspartame (ASP) at two different doses for 4 weeks induces oxidative stress, inflammation, and histopathology in the brain of rats. This study also focused on explaining whether L-carnitine (LC) has potential ameliorative effects against pathophysiology induced by ASP in the brain. Adult male Wistar rats were split into six groups as follows: control animals were administered with vehicle, group of ASP at a low dose (ASP-LD) was given $75 \mathrm{mg} / \mathrm{kg}$ B.W., high dose of ASP (ASP-HD; $150 \mathrm{mg} / \mathrm{kg}$ ), animals were treated with LC $(10 \mathrm{mg} / \mathrm{kg}), A S P-L D+L C$ group and ASP-HD + LC treated rats.

Results: ASP induced large increments in cytokines of interleukin-6, tumor necrosis factor-a, myeloperoxidase, xanthine oxidase, cyclooxygenase-2, and prostaglandin E2 in a dose-dependent response of the brain. Activities of superoxide dismutase/catalase, glutathione peroxidase, and acetylcholinesterase, besides levels of thiol, glutathione, a brain-derived neurotrophic factor, and neurotransmitters, were decreased in the brain tissue. The inauguration of brain injury by ASP administration was depended on the dose of treatment. Co-administration of LC with ASP significantly reversed and corrected all the abovementioned parameters.
\end{abstract}

Conclusion: The data confirm that LC attenuated ASP neurotoxicity by suppressing the inflammation, oxidative stress and improving the neurotransmitters, antioxidants coupled with the histological and cellular structure.

Keywords: Brain injury, Xanthine oxidase, Cyclooxygenase-2, Brain-derived neurotrophic factor, Rat

\section{Background}

Aspartame (ASP) consists of two amino acids, L-aspartic and L-phenylalanine. It is an advocate by the Food and Drug Administration (FDA) in 1981 (Abdallah, 2002). It is commonly used among diverse foods, medicines, and hygiene products as artificial sweeteners (Abhilash, Paul, Varghese, \& Nair, 2011; Mourad \& Noor, 2011; NostiPalacios et al., 2014; Ashok, Sheeladevi, \& Wankhar, 2015; Choudhary \& Devi, 2015; Prakash, Jaspreet Kaur Kalra, \& Kumar, 2015). It is not only used for diabetic and obese people but also for healthy people and children. The exposure of the rats to a dose of ASP resulted in detectable methanol after $24 \mathrm{~h}$ that is liable for the

\footnotetext{
*Correspondence: elshenawy_nahla@hotmail.com

${ }^{3}$ Zoology Department, Faculty of Science, Suez Canal University, Ismailia 41522, Egypt

Full list of author information is available at the end of the article
}

production of oxidative stress in the brain regions (Ashok et al., 2015). The central nervous system (CNS) is unprotected from free radical injury because the brain is consuming high levels of oxygen, containing a rich amount of lipid, and it has a deficiency of antioxidant enzymes comparing to other tissues (Ashok et al., 2015). The glutathione-dependent system is involved in the mechanism of long-term ASP toxicity on the brain by impairment of the antioxidant/pro-oxidant status (Abhilash et al., 2011).

ASP is metabolized to phenylalanine, methanol, and aspartic acid (Mourad \& Noor, 2011); the latter metabolite is reported to be excitotoxic (Prakash et al., 2015). Moreover, there is an increment of the levels of phenylalanine which is a precursor of catecholamine that caused damage to the brain (Nosti-Palacios et al., 2014). The methanol is converted to formaldehyde, then to 
formic acid which has been proved to cause systemic toxicity (Choudhary \& Devi, 2015). Additionally, methanol and its metabolites are behind the initiation of oxidative stress in the brain (Iyyaswamy \& Rathinasamy, 2012). ASP was found to be potentially toxic (Whitehouse, Boullata, \& McCauley, 2008) and carcinogenic (Soffritti, Belpoggi, Tibaldi, Esposti, \& Lauriola, 2007) even at the acceptable daily intake (ADI) for humans.

Exposure of rats to ASP for a long time induced hepatocellular injury and alterations in the liver (Abhilash et al., 2011) and kidney (Hamza, Al-Eisa, Mehana, \& ElShenawy, 2018) antioxidant status accompanied by histological alterations (Hamza et al., 2018; Alkafafy, Ibrahim, Ahmed, \& El-Shazly, 2015).

Cyclooxygenase-2 (COX-2) protects the brain by decreasing reactive radical formation. COX-2 is found in inflammatory cells and the brain. Under pathologic conditions as trauma, COX-2 activity is increased, producing reactive oxygen species (ROS) and toxic prostaglandin metabolites (Graham \& Hickey, 2003). Moreover, brain-derived neurotrophic factor (BDNF) is responsible for the control of neuronal cell growth and long-term memory (Allen et al., 2013) besides changing the morphology of neurons (Kir, Şahin, Öztaş, Musul, \& Kuskay, 2013).

L-carnitine (LC) is formed from exogenous sources (75\%) and endogenous biosynthesis (25\%) in the human body from lysine and methionine in the liver, kidneys, and brain tissue (Cayir et al., 2009). Many investigators reported that LC plays an important role in the oxidative/antioxidative balance of different organs (Ulvi et al., 2011; Siktar, Ekinci, Beydemir, Gulcin, \& Gunay, 2011; Hamza et al., 2018) and responsible to transport longchain fatty acids into the mitochondria, where they are oxidized to produce adenosine triphosphate (Aleisa et al., 2007).

However, the anti-peroxidative effect of LC on different tissues (Bayraktar et al., 2008; Cayir et al., 2009; Siktar et al., 2011) and its action on antioxidant enzymes, such as glutathione peroxidase (GPx) and catalase (CAT), have been reported in some studies (Cetinkaya et al., 2006; Siktar et al., 2011; Hamza et al., 2018). These enzymatic antioxidants are very important as a natural enzymatic defense system that detoxifies $\mathrm{H}_{2} \mathrm{O}_{2}$ into the water. LC improved the damage of white matter after chronic hypoperfusion in rats (Ueno et al., 2015) and provided neuroprotection in aging rats by elevating the brain antioxidant ability (Juliet, Joyee, Jayaraman, Mohankumar, \& Panneerselvam, 2005). Moreover, the low-dose of LC was able to block L-thyroxine-induced oxidative stress in rat liver (Yildirim, Yildirim, Dane, Aliyev, \& Yigitoglu, 2013).

Compared to other tissues, the brain is very notable for oxidative injury because it produced a huge amount of polyunsaturated fatty acids and less antioxidant defense system (Butterfield \& Stadtman, 1997). Therefore, the study aimed to evaluate whether the LC administration could protect the brain tissue from oxidative stress and neurotoxicity induced by ASP in rats. Many important parameters were determined to prove this goal as the brain markers (cyclooxygenase-2, brainderived neurotrophic factor, and prostaglandin 2), cytokines (IL-6 and TNF- $\alpha$ ), serotonin, catecholamine (dopamine, norepinephrine, and epinephrine), acetylcholinesterase, and some oxidant-antioxidant parameters (myeloperoxidase, xanthine oxidase, superoxide dismutase, catalase, glutathione peroxidase, glutathione, and thiol content).

\section{Materials and methods \\ Chemicals}

ASP was bought from Sigma-Aldrich Chemical; St. Louis, USA. The ELISA kit of rat brain-derived neurotrophic factor was secured from WKEA Co. (USA). The ELISA kit of cyclooxygenase-2 (COX-2), prostaglandin E2 (PGE2), and cytokines (IL-6 and TNF- $\alpha$ ) were available from Immuno-Biological Laboratories Co., Ltd (IBL), USA.

\section{Animal model}

The Wistar albino male rats were obtained from the animal house of Faculty Veterinary Medicine, Zagazig University. The rats were housed under $12 / 12 \mathrm{~h}$ light/dark exposure. Rats were weighing approximately $200-250 \mathrm{~g}$. The European Community Directive (2010/63/EU) on the protection of animals used for scientific purposes and national rules on animal care were followed during the study. The study protocol was approved by the Animal Welfare Act and the Guide for the Care and the Use of Laboratory Animals established by Zagazig University, Zagazig, Egypt. Animal experiments received approval from the Ethical Committee (No. P22/2/2013).

\section{Experimental design}

The rats were randomly divided into six groups with eight animals in each one as the following: control animals were administered with saline as vehicle, low dose of ASP (ASP-LD, $75 \mathrm{mg} / \mathrm{kg}$ ), high dose of ASP (ASP$\mathrm{HD}, 150 \mathrm{mg} / \mathrm{kg})$, LC $(10 \mathrm{mg} / \mathrm{kg})$, ASP-LD + LC, and ASP-HD + LC. The doses of ASP and LC were chosen according to previous studies (Iyyaswamy \& Rathinasamy, 2012 and Elshazly, Ahmed, Hassan, \& Ibrahim, 2012, respectively). ASP-LD was selected to keep the dosage within the human exposure limit. The rats were treated orally for 4 weeks daily. LC was given first then after $30 \mathrm{~min}$, ASP was administrated. Blood samples were collected for determination of acetylcholinesterase (AChE) activity where $\mathrm{AChE}$ is anchored to the external surface of the RBC. 
Estimation of brain markers (BDNF, COX-2, prostaglandin E2) and cytokines in the brain-homogenates

The whole-brain of each animal was quickly removed and washed in ice-cold saline and rapidly transferred to an ice-cold Petri dish and dissected to obtain the brain. For the determination of BDNF, COX-2, prostaglandin E2 (PGE2), and cytokines (IL-6 and TNF- $\alpha$ ), $100 \mathrm{mg}$ of the brain was homogenized in two volumes of $0.01 \mathrm{~mol} /$ $\mathrm{L}$ phosphate-buffered saline (PBS) containing 0.05\% Tween-20. After homogenization and centrifugation at $10,000 \times g$ at $4{ }^{\circ} \mathrm{C}$ for $20 \mathrm{~min}$, the resultant supernatant was collected and stored at $-80^{\circ} \mathrm{C}$ until analysis for measuring BDNF, COX-2, PGE2, IL- 6 , and TNF- $\alpha$.

\section{Peroxidation and antioxidants}

Myeloperoxidase (MPO) activity was determined in the brain homogenates (Suzuki, Tanaka, \& Kawamura, 1983). Xanthine oxidase (XO) activity was assayed (Prajda \& Weber, 1975), based on the formation of uric acid from xanthine. One unit of XO activity was defined as $1 \mu \mathrm{mol}$ of uric acid formed/minute, and data are presented as units/milligram protein.

Superoxide dismutase (SOD) and catalase (CAT) were evaluated in the brain homogenates (Marklund \& Marklund, 1974; Aebi, 1974, respectively). The activity of glutathione peroxidase (GPx) was estimated (Hafeman, Sunde, \& Hoekstra, 1974). Reduced glutathione (GSH) and total thiol levels were estimated (Beutler, Olga, \& Kelly, 1963; Hu, 1994) in the brain homogenates, respectively.

\section{Protein determination in tissue}

The protein content of tissue samples were measured by the method of Bradford (29) using bovine serum albumin as a standard The protein content of tissue samples was assessed using Bradford assay (Marklund \& Marklund, 1974) where bovine serum albumin was used as a standard.

\section{Preparation of brain and extraction of neurotransmitters}

Rats were killed by sudden decapitation at the designed times after 4 weeks of treatment. The brain was rapidly and carefully excised and then dissected on dry ice glass plate between 8:00 and 9:00 a.m. for all the groups. The brain of the rat was weighed and homogenized in an icecold solution of acidified n-butanol to obtain 10\% homogenate. The duplicate internal standard of serotonin, norepinephrine, and dopamine was prepared by adding $0.3 \mathrm{~mL}$ standard mixture $(0.1 \mathrm{~mL}$ containing $100 \mu \mathrm{g}$ of each amine) to $9.7 \mathrm{~mL}$ of $0.2 \mathrm{~N}$ acetic acid. Aliquots of $0.2 \mathrm{~mL}$ of this solution were diluted to $0.3 \mathrm{~mL}$ with $0.2 \mathrm{~N}$ acetic acid then received $3 \mathrm{~mL}$ of acidified n-butanol $(0.85 \mathrm{~mL}$ of concentrated $\mathrm{HCl} / \mathrm{L}$ n-butanol) and internal standard tubes were centrifuged at $10,000 \times g$ for $5 \mathrm{~min}$.
The aqueous phase was collected and divided into portions, the first was used for the determination of serotonin while the other for the assessment of epinephrine, norepinephrine, and dopamine by using highperformance liquid chromatography (HPLC)-mass spectrometry (MS) method.

\section{Estimation of neurotransmitter}

Serotonin content was carried out depending on the reaction of ortho-phthalaldehyde (Ciarlone, 1978). The epinephrine, norepinephrine, and dopamine were estimated by the method that depends on the oxidation by iodine that consists of acetic acid $(5 \mathrm{~N})$, alcoholic iodine solution $(0.1 \mathrm{~N})$, disodium ethylene diamine tetra-acetic acid dehydrate $(0.1 \mathrm{~N})$ in sodium acetate $(\mathrm{pH} 6.7-7)$, and alkaline sulfite $(5 \mathrm{~N})$ that prepared just before use (Ciarlone, 1978).

\section{Estimation of acetylcholinesterase}

Acetylcholinesterase (AChE) in the serum was estimated by the kit of Biodiagnostic Company, Dokki, Giza, Egypt (Magnotti, Eberly, \& McConnell, 1988).

\section{Histological and electron microscopic evaluation}

Parts of the brain were fixed in formalin (10\%) and embedded in paraffin, sectioned, and then stained with hematoxylin and eosin (Gabe, 1968). The sections were examined by light microscope and photographed using a digital camera.

For the ultrastructure examination, the tissues were fixed in $2.5 \%$ glutaraldehyde for $24-48 \mathrm{~h}$. The specimens were washed in phosphate buffer ( $\mathrm{pH} 7.2-7.4)$ 3-4 times for $20 \mathrm{~min}$ every time and post-fixed in $1 \%$ osmium tetroxide for $2 \mathrm{~h}$. Fixed specimens were dehydrated in ascending ethyl alcohol grades, cleared in propylene oxide, and embedded in Epon resin (Weakley \& Beginner, 1981).

Semi-thin sections $(1 \mu \mathrm{m}$ thick) were stained with toluidine blue for $2 \mathrm{~min}$ and examined by the use of a light microscope. The resin blocks were retimed to get rid of the undesired tissue. Ultrathin sections (60-90 nm thick) and representative fields of semi-thin sections were selected and were cut with a diamond knife using a Reichert OMVs ultra-microtome, mounted on copper grids and double-stained with uranyl acetate and lead citrate (Weakley \& Beginner, 1981). The grids were examined and photographed using a transmission electron microscope (JEOL JEM-1200 EX II, Japan) operated at $60-70 \mathrm{kV}$, Faculty of Agriculture (Electron microscope unit), Mansoura University, Egypt.

\section{Statistical analysis}

Values are expressed as the means \pm SE of $(n=8)$ determinations. The data for various biochemical parameters 
were analyzed by one-way analysis of variance followed by Duncan's multiple range test using the statistical software package SPSS version 17.0, Chicago, USA. $p$ values $<0.05$ were counted as statistically significant.

\section{Results}

\section{Biochemical assessment}

$\mathrm{MPO}$ and XO activities were the increment in ASPtreated groups and they decreased when the rats are treated with LC before ASP (Table 1)

The GPx activity in the LC-treated rats did not differ from the controls (Table 1). However, the ASP-treated rats showed a marked diminish in GPx activity from control and LC-treated rats.

The SOD and CAT activity in the LC-treated rats did not change the controls (Table 1). The activity of both of them decreased significantly after treatment of the rats with both doses of ASP. However, exposure of the rats to ASP after LC showed a significant elevation in the SOD and CAT activities as compared to the ASP group alone.

The protein thiol levels in the LC-treated animals did not differ from the control as shown in Table 1. ASP declined the level of thiol in treated rats. However, the administration of LC to the ASP-treated rats showed a significant rise in the protein thiol levels as compared to its ASP group.

The GSH levels in the LC and control rats were almost the same (Table 1). The GSH level has a significant drop in ASP groups than control rats $(p<0.05)$. LC with ASP groups showed a significant rise in GSH level as compared with its related group of ASP alone.

The ASP significantly decreased the level of BDNF by $41.4 \%$ and $59.5 \%$ for ASP-LD and ASP-HD groups as compared to control animals, respectively (Table 2). There were significant increments in the levels of COX2 and PGE2 in rats after 4 weeks of exposure. COX-2 increased by 2.3- and 3.3-fold, while PGE increased by 1.8and 2.2-fold for ASP-LD and ASP-HD groups, respectively. Treatment of rats with LC and ASP-LD or ASP-HD improved all the previous parameters to almost the control value.

The results revealed that the administration of the two doses of ASP showed significant elevation of brain cytokines (TNF- $\alpha$ and IL-6) of rats after 4 weeks of treatment as compared to control animals (Fig. 1). Treating the rats with LC with ASP for 28 ameliorated the levels of cytokines in the brain tissue when compared with their levels in the rats of the ASP group only.

The effect of ASP on the major monoamine neurotransmitters (serotonin, dopamine, norepinephrine, and epinephrine) was summarized in Fig. 2. The levels of these neurotransmitters were decreased significantly as the effect of ASP. Administration of LC before ASP restored the depletion of neurotransmitters.

There was a significant reduction in the activity of AChE as the effect of ASP (Fig. 3). The AChE activity significantly improved as the effect of LC with different doses of ASP.

\section{Histopathological assessment}

Figure 4 presents the effect of $\mathrm{LC}$ on the brain tissue treated with ASP for 4 weeks. The normal arrangement of layers of neurons and neuronal fibers is shown in Fig. $4 \mathrm{a}$ and $\mathrm{b}$ for control and LC groups, respectively. The layers of the brain consist of the outer molecular layer, the external granular layer, the external pyramidal layer, the inner granular layer, the inner pyramidal, and the polymorphic layer. The pyramidal cells of the external pyramidal layer showed open face nuclei and basophilic cytoplasm. However, the neuroglia cells and blood capillaries were scattered between neurons.

After treatment, the animals with ASP-LD, the moderate area of hemorrhage and necrosis, were recognized in the brain tissue (Fig. 4c). Treatment of rats with ASPHD showed a large area of hemorrhage and necrotic areas of the brain with the congested area (Fig. 4d). Some pyramidal cells were darkly stained, while some

Table 1 Effect of L-carnitine on antioxidant enzymes, glutathione and thiol level in the brain of male rats treated with aspartame

\begin{tabular}{lllllll}
\hline Parameters & Control & LC & ASP-LD & ASP-HD & ASP-LD and LC & ASP-HD and LC \\
\hline MPO (nmol/min/mL) & $26.6 \pm 0.8$ & $27.7 \pm 0.8$ & $36.9 \pm 1.9^{\mathrm{a}}$ & $38.5 \pm 2.1^{\mathrm{a}}$ & $30.0 \pm 1.9^{\mathrm{b}}$ & $32.0 \pm 1.4^{\mathrm{b}}$ \\
XO (U/g tissue) & $16.5 \pm 0.8$ & $16.2 \pm 0.5$ & $31.0 \pm 1.8^{\mathrm{a}}$ & $35.2 \pm 1.6^{\mathrm{a}}$ & $24.2 \pm 1.5^{\mathrm{b}}$ & $27.9 \pm 0.9^{\mathrm{b}}$ \\
SOD (nmol/g tissue) & $25.9 \pm 0.9$ & $26.1 \pm 0.9$ & $11.4 \pm 0.5^{\mathrm{a}}$ & $9.7 \pm 0.8^{\mathrm{a}}$ & $17.5 \pm 1.3^{\mathrm{b}}$ & $16.9 \pm 0.9^{\mathrm{b}}$ \\
CAT (U/g tissue) & $5.9 \pm 0.1$ & $6.2 \pm 0.4$ & $2.7 \pm 0.2^{\mathrm{a}}$ & $1.7 \pm 0.4^{\mathrm{a}}$ & $4.1 \pm 0.2$ & $3.6 \pm 0.2$ \\
GPx (mol/g tissue) & $20.81 \pm 1.5$ & $24.17 \pm 1.6$ & $13.34 \pm 0.4^{\mathrm{a}}$ & $12.34 \pm 0.7^{\mathrm{a}}$ & $17.65 \pm 0.9^{\mathrm{b}}$ & $15.78 \pm 0.5^{\mathrm{b}}$ \\
Thiol ( $\mu \mathrm{mol} / \mathrm{g}$ tissue) & $11.1 \pm 1.1$ & $11.8 \pm 1.4$ & $6.2 \pm 1.0^{\mathrm{a}}$ & $5.3 \pm 1.1^{\mathrm{a}}$ & $12.2 \pm 1.6$ & $10.1 \pm 1.7$ \\
GSH (mol/g tissue) & $15.9 \pm 0.5$ & $16.2 \pm 0.5$ & $9.5 \pm 0.6^{\mathrm{a}}$ & $9.8 \pm 0.8^{\mathrm{a}}$ & $13.5 \pm 0.5^{\mathrm{b}}$ & $13.1 \pm 0.5^{\mathrm{b}}$ \\
\hline
\end{tabular}

Values are expressed as means $\pm \mathrm{SE} ; n=8$ for each treatment group

LC L-carnitine, ASP-LD a low dose of aspartame, ASP-HD high dose of aspartame, MPO myeloperoxidase, $X O$ xanthine oxidase, SOD superoxide dismutase, $C A T$ catalase, GPx glutathione peroxidase, GSH reduced glutathione

${ }^{a}$ Significant difference as compared to control

${ }^{\mathrm{b}}$ Significant difference as compared to its relative group of ASP $(P \leq 0.05)$ 
Table 2 Effect of L-carnitine on BDNF, COX-2, and PGE2 in the brain of male rats treated with aspartame

\begin{tabular}{lllllll}
\hline Parameters & Control & LC & ASP-LD & ASP-HD & ASP-LD and LC & ASP-HD and LC \\
\hline BDNF (pg/mg tissue) & $55.1 \pm 1.7$ & $57.5 \pm 0.9$ & $32.3 \pm 0.8^{\mathrm{a}}$ & $22.3 \pm 0.7^{\mathrm{a}, \mathrm{b}}$ & $44.37 \pm 1.6^{\mathrm{c}}$ & $42.2 \pm 0.7^{\mathrm{c}}$ \\
COX-2 (ng/mg tissue) & $0.7 \pm 0.1$ & $0.8 \pm 0.1$ & $1.6 \pm 0.1^{\mathrm{a}}$ & $2.3 \pm 0.1^{\mathrm{a}, \mathrm{b}}$ & $0.8 \pm 0.1^{\mathrm{c}}$ & $0.9 \pm 0.1$ \\
PGE2 (pg/mg tissue) & $13.1 \pm 0.6$ & $12.9 \pm 0.6$ & $23.8 \pm 0.4^{\mathrm{a}}$ & $29.1 \pm 0.7^{\mathrm{a}, \mathrm{b}}$ & $16.7 \pm 1.7^{\mathrm{c}}$ & $18.2 \pm 0.8$ \\
\hline
\end{tabular}

Values are expressed as mean $\pm \mathrm{SE}, n=8$

LC L-carnitine, ASP-LD a low dose of aspartame, ASP-HD a high dose of aspartame, BDNF brain-derived neuroatrophic factor, COX-2 cyclooxygenase-2, PGE2 prostaglandin E2

a Significant difference as compared to control

${ }^{b}$ Significant difference as compared to ASP-LD

'Significant difference as compared to its relative group of ASP $(P \leq 0.05)$.

others appeared with faintly stained cytoplasm and nuclei.

Figure 4e presents the effect of ASP-LD with LC on the brain tissue, where much reduced congested areas with normal neural fibers were observed. ASP-HD with LC caused recovery of the congested area with a moderate area of necrosis and normal appearance to fibers.

\section{Semi section assessment}

Figure 5 presented the semi-thin sections of the brain tissue with toluidine blue stain in rats treated with ASP with/without LC. Control normal brain tissues with normal white matter and neurons were observed (Fig. 5a). Toluidine blue-stained semi-thin sections showed the pyramidal cells with large vesicular nuclei and darkly stained cytoplasm containing Nissl's granules. LCtreated rats showed the normal appearance of brain tissues with normal neurons and glial fibers (Fig. 5b).

In ASP-LD-treated animals, the necrotic zone and enlarged swollen glial fibers appeared (Fig. 5c). ASP-HD rats showed that the brain tissues had a necrotic zone and highly congested blood vessels with vacuoles and enlarged blood capillary (Fig. 5d). Stained semi-thin sections showed pyramidal cells appeared deeply stained and irregular in shape.
ASP-LD + LC group showed the brain tissues with less necrotic zone and normal glial fibers with perinuclear Golgi complex (Fig. 5d). In the rats that are treated with ASP-HD + LC, the brain tissues appeared with normal glial fibers and less necrotic area with some fatty change.

\section{Transmission electron microscopic assessment}

Transmission electron microscopy of a brain section of the control group was presented in Fig. 6a. The normal appearance of the white matter of the brain and nucleus with the homogeneous dispersal of the chromatin was observed. Sized mitochondrial, neurons, and structure of Purkinje cells with well cytological structures appeared. Higher magnification revealed also the cytoplasm studded with rough endoplasmic reticulum and Golgi complex.

Treatment of rats with LC showed the normal occurrence of the white matter of the brain, nucleus, and blood capillary with all normal structures as a control group (Fig. 6v).

Treatment of animals with ASP-LD showed junctions between the capillary wall and neuropil with the tight wall without any disintegration or edema (Fig. 7a). Moreover, pycnotic Purkinje cells appeared with irregular boundaries and abundant crystallized mitochondria

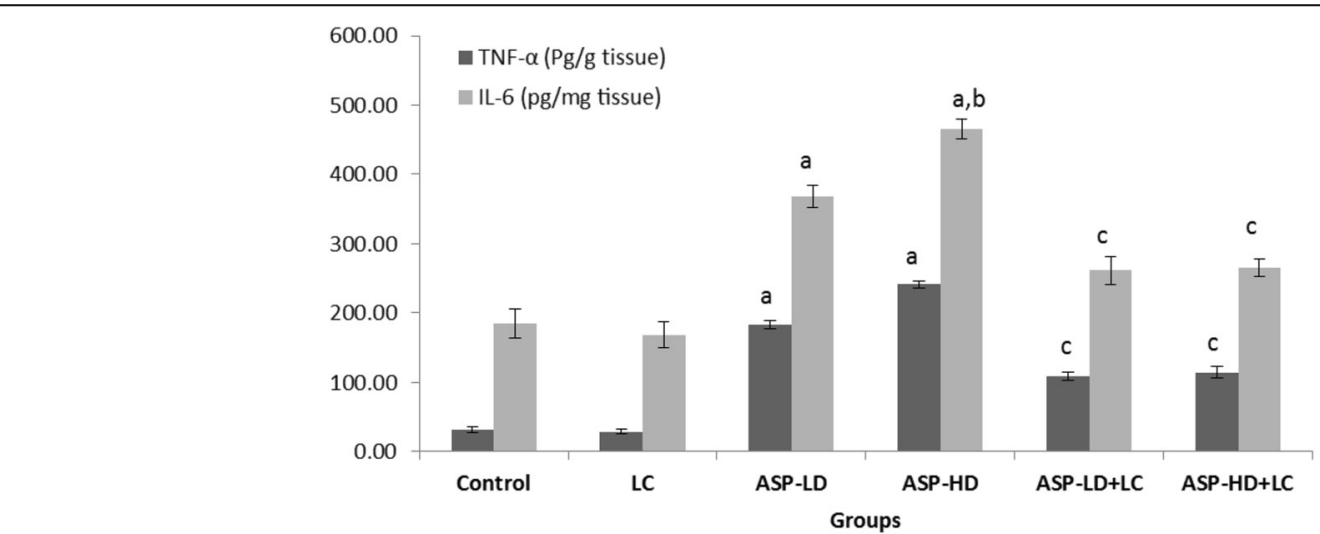

Fig. 1 Effect of L-Carnitine on TNF- $a$ and IL- 6 in the brain of male rats treated with aspartame. Values are expressed as mean $\pm S E, n=8$. The significant value

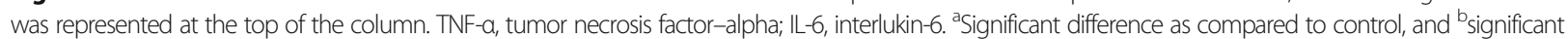
difference as compared to ASP-LD. 'Significant difference as compared to its relative group of ASP ( $P \leq 0.05)$ 


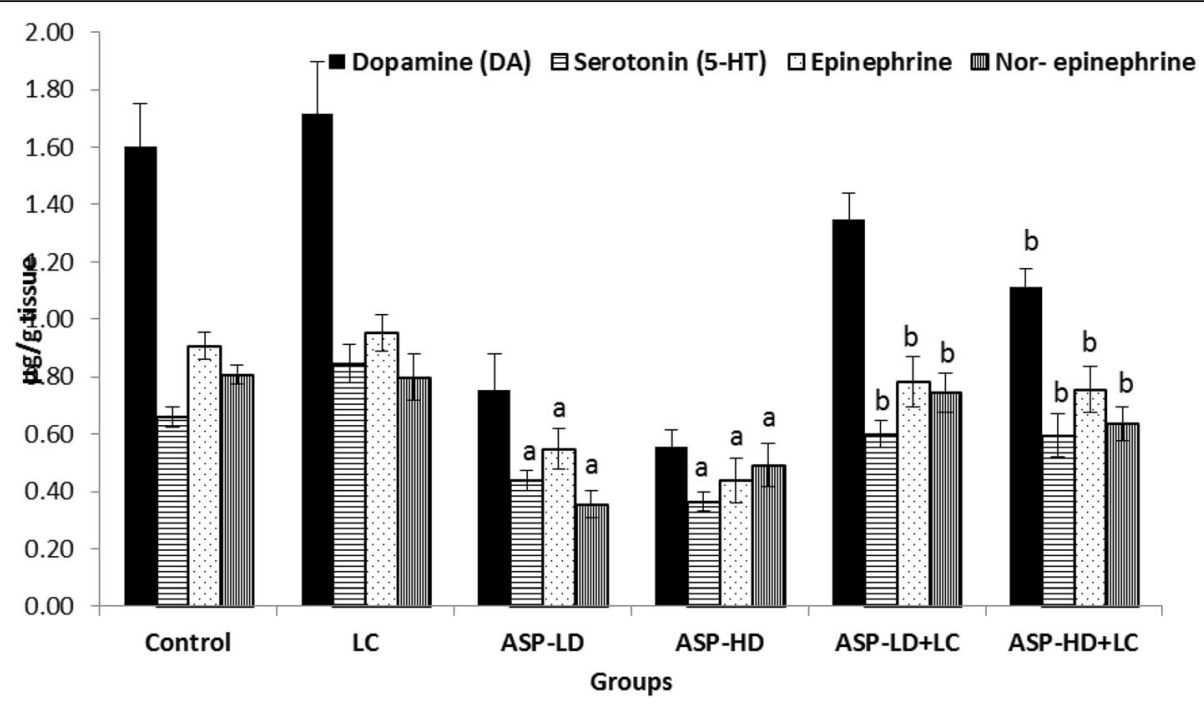

Fig. 2: Effect of L-carnitine on some neurotransmitter in the brain of male rats treated with aspartame. Values are expressed as mean $\pm S E, n=8$. The value of the significant was represented at the top of the column. ${ }^{a}$ Significant difference as compared to control, and ${ }^{\mathrm{b}}$ significant difference as compared to its relative group of ASP ( $P \leq 0.05)$.

coupled with the fragmented rough endoplasmic reticulum. The disintegration junction capillary wall between the capillary wall and astrocytic perivascular edema with the appearance of more vacuoles and vesiculated rough endoplasmic reticulum were recognized.

TEM of the brain of the animals treated with ASP-HD showed Purkinje cell with karyolysis nuclei and apoptotic appearance with very irregular boundaries (Fig. 7b). The convolution of the nuclear envelope with the disintegration of nuclear chromatin besides having cytoplasm with reduced mitochondrial and some crystallize. The capillary junction between the capillary wall and astrocytic perivascular edema and thickening were observed. The junction wall with very abnormal convolution appearance and congested blood vessels with moderate hemorrhage and vacuoles have been observed.

TEM of rats treated with a combination of ASP-LD and LC showed amelioration in the cytoplasmic

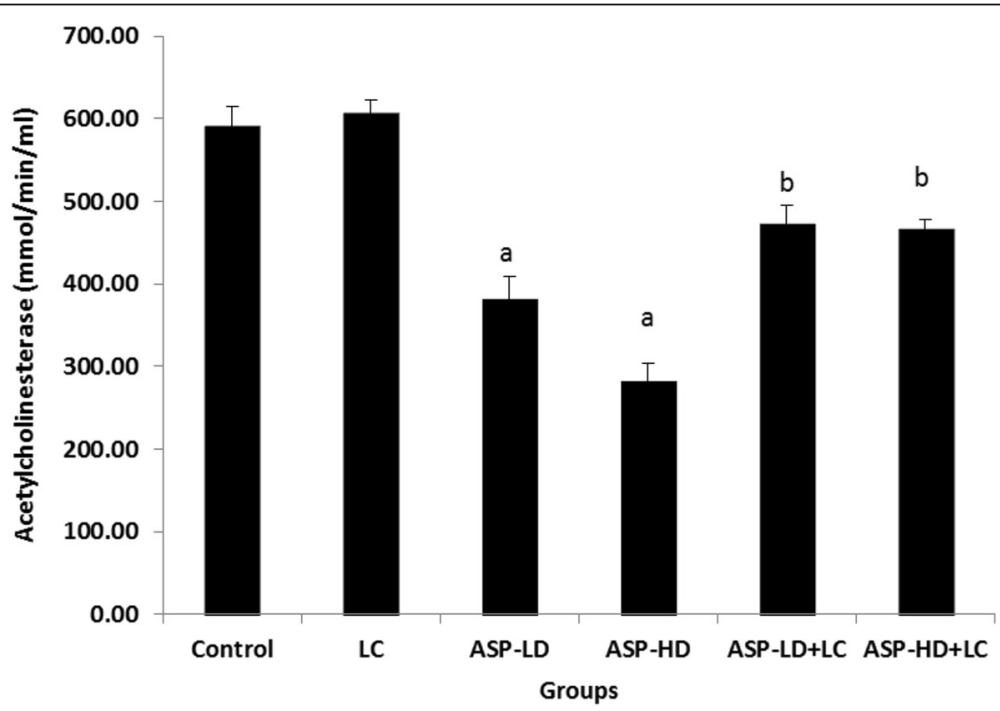

Fig. 3 Effect of L-carnitine on acetylcholinesterase in the serum of male rats treated with aspartame. Values are expressed as mean $\pm \mathrm{SE}, n=8$. The value of the significant was represented at the top of the column. ${ }^{a}$ Significant difference as compared to control, and ${ }^{b}$ Significant difference as compared to its relative group of ASP $(P \leq 0.05)$ 

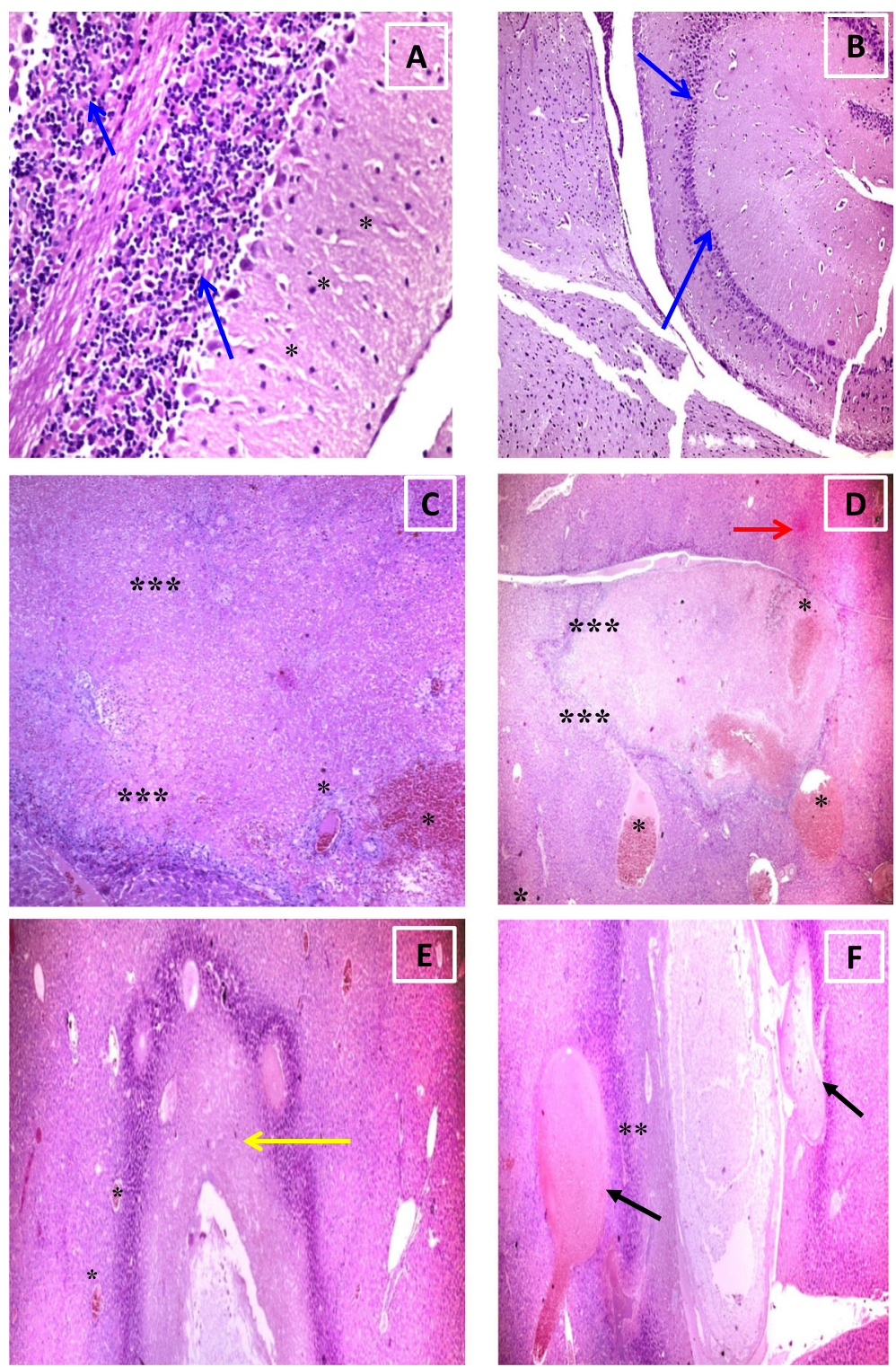

Fig. 4 Histopathological of the brain stained with hematoxylin and eosin in a control groups of rat showing normal arrangement of layers of neurons (blue arrow) and neuronal fibers $\left(^{*}\right) ; \mathbf{b}$ cross-section of rat brain treated with L-carnitine $(10 \mathrm{mg} / \mathrm{kg})$ showing normal white matter with normal neurons (blue arrow) and neuronal fibers $(*)$; c aspartame low dose group $(75 \mathrm{mg} / \mathrm{kg})$ showing moderate area of hemorrhage $\left(^{*}\right)$ and necrosis $\left(^{* *}\right)$ in the brain; $\mathbf{d}$ aspartame high dose rats $(150 \mathrm{mg} / \mathrm{kg})$ showing large area of hemorrhage $\left(^{*}\right)$ and necrotic areas of the brain $\left(^{* * *}\right)$ with congested area (red arrow); e low dose of aspartame and L-carnitine-treated group showing very reduced congested area $\left({ }^{*}\right)$ with normal neural fibers (yellow arrow); $\mathbf{f}$ high dose of aspartame and L-carnitine showing the recovery of the congested area with moderate area of necrosis (black arrow) with normal appearance to fibers $\left.{ }^{* *}\right)$ and reduced necrotic neurons $(\times 400($

organelles like the nucleus return to its rounded normal shape with the normal nuclear membrane and homogenous distribution of chromatin (Fig. 8a). The endoplasmic reticulum, small mitochondria, and appearance of normal neurons were observed.

Treatment the rats with ASP-HD and LC showed restoration of the normal shape of the nuclei and nuclear envelope (Fig. 8b). The capillary became constricted by decreasing the hemorrhage area. The tight junction had some enlargement but without edema as well as normalsized mitochondria with some large vacuoles.

\section{Discussion}

There are no data available on the precautionary effects of LC against the toxicity induced by ASP in rat brain tissue. Therefore, the toxic effects, biochemical variations, and histopathology in the brain of rats as regards the low and high doses of ASP were investigated. 

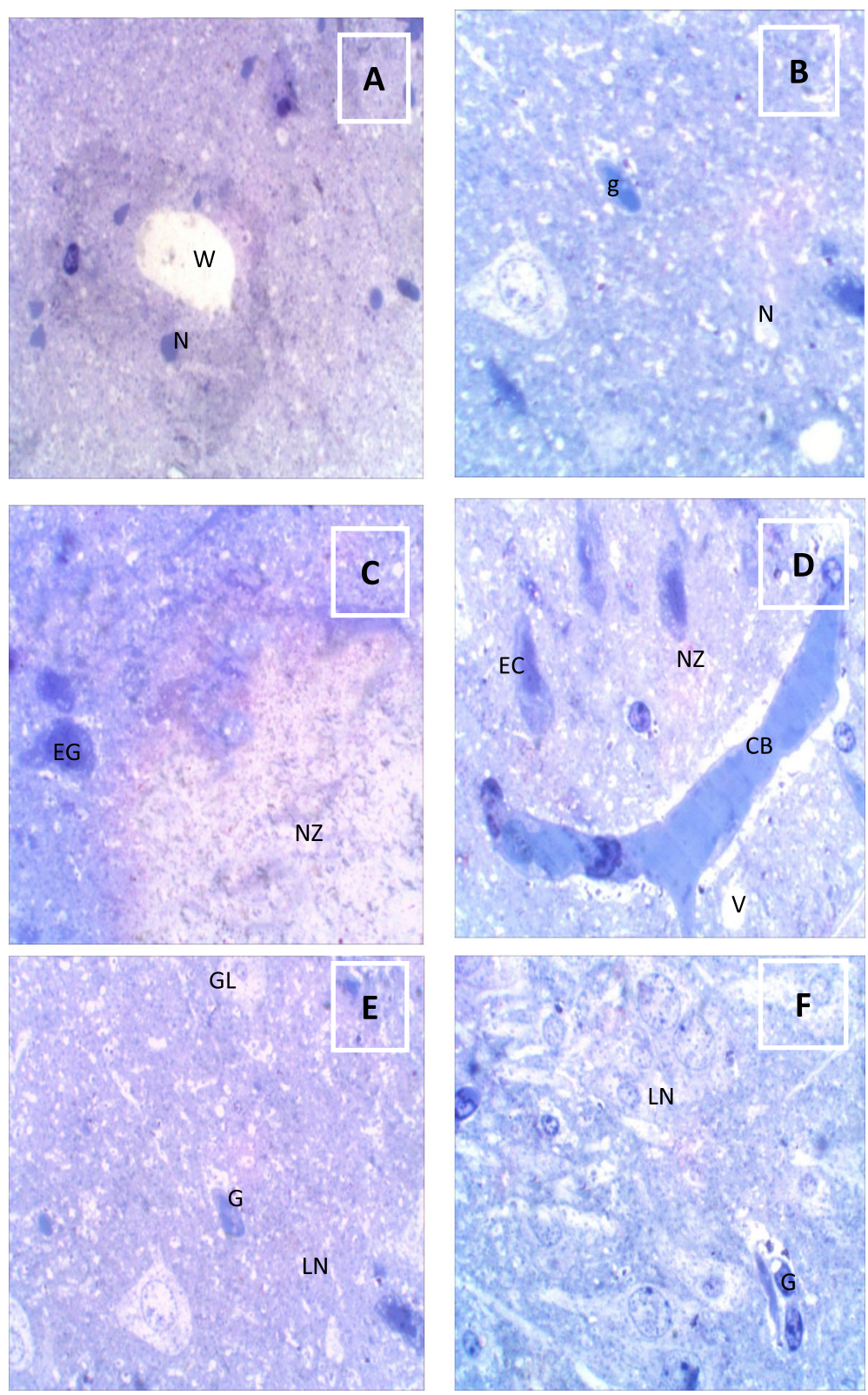

Fig. 5 Semi thin sections of the brain with toluidine blue stain. a Control normal appearance of brain tissues with normal white matter (W) and neurons. b LC-treated rats showed normal appearance of brain tissues with normal neurons ( $N$ ) and glial fibers (g). c ASP-LD treated-animals, necrotic zone (NZ), and enlarged swollen glial fibers (EG) appeared. d ASP-HD group showed that the brain tissues had necrotic zone (NZ) and highly congested blood vessel (CB) with vacuoles $(V$ ) and enlarged blood capillary (EC). e ASP-LD + LC group showed the brain tissues with less necrotic zone (LN) and normal glial fibers (G) with perinuclear Golgi complex (GL). f ASP-HD + LC: Brain tissues with normal appearance of brain tissues and normal glial fibers (G) and less necrotic area (LN) with some fatty change

Moreover, the neuroprotection of LC is evident in biochemical, histological, and TEM assessment.

The endogenous antioxidant mechanisms play an important role to prevent oxidative stress of ASP. When there is an imbalance in this defense system, brain tissue damage occurs. Therefore, it is crucial to encourage the endogenous defense mechanism by using exogenous antioxidant agents as LC.

In the current study, there were marked elevations in free radicals as indicated by ameliorating the MPO, XO, COX-2, PEG2, TNF- $\alpha$, and IL- 6 in a dose-dependent attitude to ASP. Furthermore, activities of SOD, CAT, 

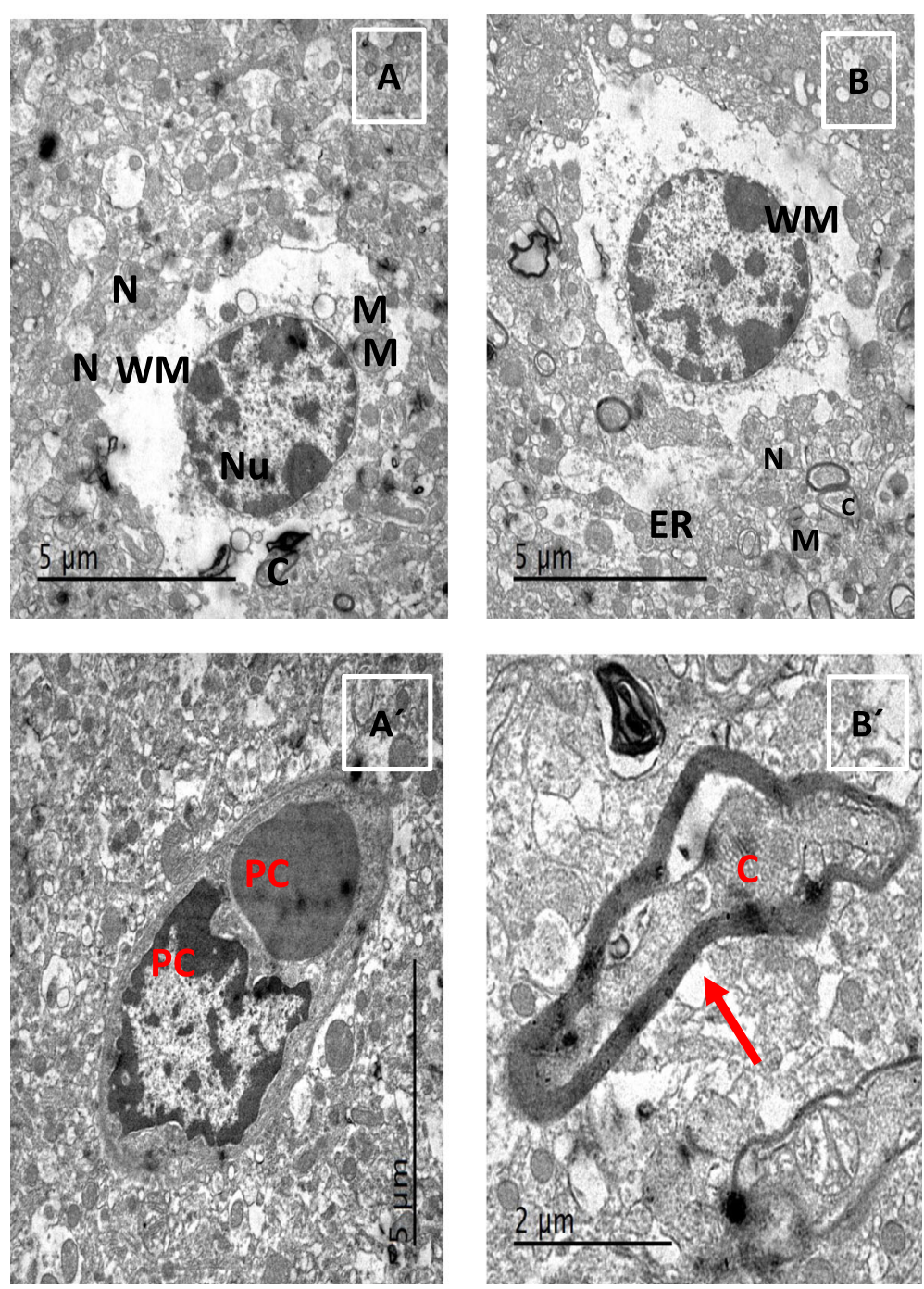

Fig. 6 Transmission electron microscope of brain section in control and LC groups. a Control group; normal appearance of white matter of the brain (WM) and normal nucleus (Nu) with homogenous distribution of the chromatin, normal size for mitochondria (M), well-defined neurons (N), and appearance of well-defined structure of Purkinje cells with well cytological structures (PC). $\mathbf{b}$ LC group showing normal appearance of WM and normal appearance of Nu with homogenous distribution of the chromatin and normal sized mitochondria (M) as well as neurons (N) and blood capillary

GPx, and AChE, besides the levels of thiol, GSH, BDNF, and neurotransmitters, were decreased in the brain tissue as the action of ASP.

MPO with $\mathrm{H}_{2} \mathrm{O}_{2}$ and chloride generates oxidant hypochlorous acid that is managed for producing the oxygendependent microbicide activity of phagocytes (Yildirim et al., 2013). Therefore, the MPO activity can be changed depending on whether the number of neutrophil leukocytes increases; it is used as an inflammatory marker. The levels of MPO were noticed to be higher in rats treated with both doses of ASP, reaffirming the hypothesis that ASP caused the inflammation.

Moreover, $\mathrm{XO}$ is generated superoxide free radical and $\mathrm{H}_{2} \mathrm{O}_{2}$ that they stimulate oxidative injury (Ates et al.,
2007). XO has been elevated as the effect of ASP; therefore, the uric acid was generated and free radicals (Kanemitsu et al., 1989). XO activity in the brain was significantly increased after harmful brain injury (Solaroglu, Okutan, Kaptanoglu, Beskonakli, \& Kilinc, 2005). In the present research, the same observation was recorded as the effect of ASP on XO activity.

SOD converts superoxide anion $\left(\mathrm{O}_{2}^{-}\right)$to hydrogen peroxide $\left(\mathrm{H}_{2} \mathrm{O}_{2}\right)$ (Akyol, Zoroglu, Armutcu, Sahin, \& Gurel, 2004), which are subsequently converted to water and oxygen by GPx or CAT. In the current study, there was a significant decline in the SOD activity after ASP treatment with an associated decrease in the CAT and GPx activities. Hence, the reduction in these enzyme 

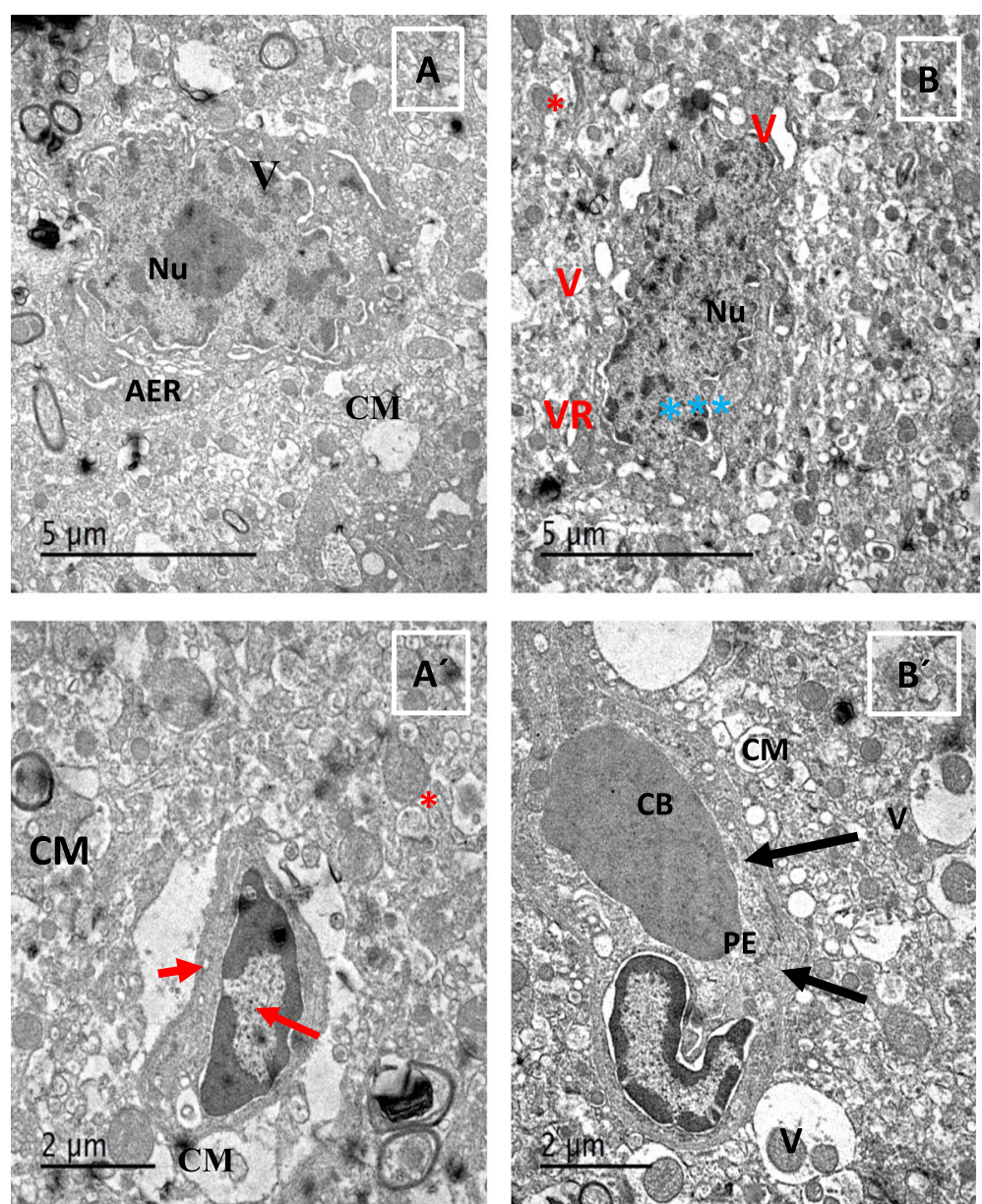

Fig. 7 Transmission electron microscope of brain section in ASP-LD and ASP-HD groups. a ASP-LD group showing junctions between capillary wall and neuropil (red arrow) with tight wall without any disintegration or edema. Pyknotic Purkinje cells appeared with irregular boundaries and abundant crystallizes mitochondria (CM) as well as fragmented rough endoplasmic reticulum (RER). Disintegration junction capillary wall between the capillary wall and astrocytic perivascular edema (PE) with the appearance of more vacuoles and vesiculated rough endoplasmic reticulum (VR). $\mathbf{b}$ TEM section of group treated with ASP-HD showing Purkinje cell with karyolysed nuclei and apoptotic appearance with irregular boundaries and convolution of the nuclear envelop with disintegration of unclear chromatin (***) having cytoplasm with very reduced mitochondria $\left(^{*}\right)$ and some crystalizes (CM) and modified cytological structures, the capillary junction between the capillary wall and astrocytic perivascular edema (PE) and thickening if the junction wall (black arrow) with very abnormal convolution appearance and congested blood vessels (CB) with moderate hemorrhage and appearance of more vacuoles

activities could be causing the elevation of free radicals and neuronal damage.

The antioxidant enzymes CAT and GPx preserve SOD against inactivation by $\mathrm{H}_{2} \mathrm{O}_{2}$. Reciprocally, SOD shelters $\mathrm{CAT}$ and GPx against superoxide anion. These regulations could have been disturbed when there is an overload of free radicals. Furthermore, the decrease in SOD and CAT activities may be due to the production of formaldehyde from the methanol. This is following a previous study that indicated formaldehyde exposure led to a reduction of SOD and CAT activities of liver tissue compared to the control (Gulec, Gurel, \& Armutcu, 2006). Besides, there was a decline in SOD activity and a dose- response relationship between formaldehyde concentration and SOD activity (Chang \& $\mathrm{Xu}, 2006$ ).

One of the most important endogenous antioxidants in all cells is GSH that removes the free radicals as hydroxyl radical, singlet oxygen, and superoxide radical. The present data are parallel to the observation of other researches (Ashok \& Sheeladevi, 2014) that found a significant fall in GSH level in the brain of rats treated with ASP at 100 and $500 \mathrm{mg} / \mathrm{kg}$ doses. Reducing GSH levels as the effect of ASP could be due to the metabolites of ASP that prevent the cell from being taken by the cysteine which is important for GSH synthesis as mentioned before (Blaylock, 2002). The depletion of GSH is one of 

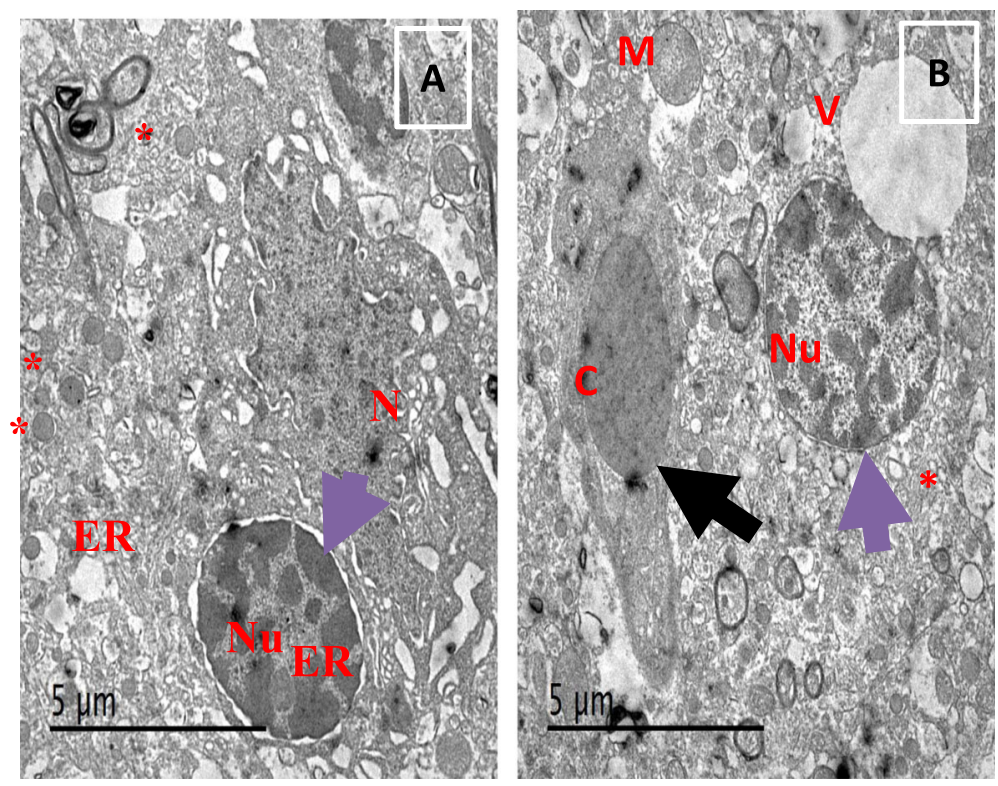

Fig. 8 Transmission electron microscope of brain section in ASP-LD and ASP-HD with LC groups. a TEM of group treated with combination of ASP-LD and LC showing amelioration in the cytoplasmic organelles as the nucleus ( $\mathrm{Nu}$ ) return to its rounded normal shape with normal nuclear membrane (head arrow) with homogenous distribution of chromatin, appearance of endoplasmic reticulum and small mitochondria $(*)$, and appearance of normal neurons (N). b TEM of group treated with combination of ASP (HD) and LC showing restoration of normal shape of the nuclei $(\mathrm{N})$ with nuclear envelope (head arrow), The capillary (C) become very constricted and decreasing the hemorrhage area with appearance of tight junction with some enlargement but without edema (black arrow), normal sized mitochondria (M) but with some large vacuoles ( $V$ )

the reasons for the elevation in the free radical-induced brain damage. Moreover, methanol is one of the ASP metabolites that reduced the GSH level and its related enzymes (Tsakiris, Giannoulia-Karantana, Simintzi, \& Schulpis, 2006).

The current study indicated that inhibition in GSH content in ASP-LD and ASP-HD groups may be also a result of its role to remove ROS and/or due to mitochondria and rough endoplasmic reticulum (RER) dysfunction as in Fig. $5 \mathrm{c}$ and $\mathrm{d}$ where the crystallized mitochondria and vesiculated RER were observed. These results are parallel with other authors (Ruszkiewicz \& Albrecht, 2015) who found that ASP caused oxidative stress and elevated the accumulation of toxic forms of ASP.

The significant reduction in the protein thiols after ASP treatment to the rats could be due to the oxidation of proteins, and it is also confirmed by lowering the level of GSH. Similarly, the reduction in protein thiol level of the brain tissue was reported (Iyyaswamy \& Rathinasamy, 2012) to support the current findings.

BDNF helped to support the existing neurons and differentiated the new neurons (Choudhary \& Devi, 2015). BDNF can prevent neuronal deterioration during stress (Lu, Vallabhaneni, Yin, \& Liu, 2013). In the current study, ASP decreased BDNF significantly in a dose manner suggesting that a loss in it may contribute to the neuronal dysfunction as ASP administration.
COX-2 is one of the cyclooxygenases that increased as the result of inflammation and neuronal lesion of the brain. Moreover, PGE2 is also acted as a brain marker for central nervous inflammatory responses. Therefore, the elevation of COX-2 and PGE2 indicated that ASP caused the inflammation. These results are correlated with the observations (Iyyaswamy \& Rathinasamy, 2012) that found that that ASP administration causes inflammation due to increasing the free radicals. Several mechanisms could be activated by COX-2 excessive expression as enhancing the action of PGE2 on glutamate liberate and oxidative stress-mediated injury by producing reactive species during the peroxidase activity (Minghetti, 2004). The initiation of COX2 results in increased PGE2 levels after brain injuries (Strauss, Weil, Jordan, \& Paksima, 2008).

A significant elevation of IL-6 and TNF- $\alpha$ level in ASP-LD and ASP-HD groups was observed. The ASP metabolites are the reason behind the toxicity of ASP (Choudhary \& Devi, 2015). Additionally, IL-6 and TNF$\alpha$ are essential for brain communication (Engblom, Monica, Dahlstrand, \& Blomqvist, 2002). IL-6 could cross the blood-brain barrier and help in the generation of PGE2 (Ethell \& Pasquale, 2005). Therefore, there is a positive correlation between increasing the COX-2 and IL-6 and the elevation of PGE2.

The present study found that all the neurotransmitters decreased as a result of ASP. This data opposite to that 
reported before by other investigators (Abdel-Salam et al., 2012) found that ASP metabolized to phenylalanine from the ester bond and raises dopamine levels of the brain. However, the high dose of ASP caused decreases in the dopamine level in the brain ogf the rats (AL-Awady \& Hassan, 2016). This decrease could be due to the increase of phenylalanine that blocks the transport of amino acids to the brain by subscribing to reducing dopamine and serotonin levels (Rycerz \& Jaworska-Adamu, 2013; Nweze, Mustapha, \& Olose, 2015). Moreover, phenylalanine also affects the synthesis of inhibitory monotransmitters and has been shown to mediate neurological effects (Nweze et al., 2015). Therefore, the high dose of aspartic acid causes hyperexcitability of neurons and leads to the degeneration of astrocytes and neurons (Schultz, Chehab, Malikzay, \& Halazonetis, 2000).

Increasing the oxidative stress is accompanied by alteration of the structural and functional cellular components as mitochondria, RER, and nucleus. In the present investigation, mitochondria were damaged as the effect of ASP treatment that could cause apoptosis of cells and decrease the rate of oxidative metabolism, thus lowering the levels of the neurotransmitters. Therefore, the cells (endothelium of the capillaries) become more permeable, leading to a compromised blood-brain barrier. So, oxidative stress and neurodegeneration increased. These observations are parallel to the others (Nosti-Palacios et al., 2014), and they reported that ASP leads to nucleic acid lesions and gene damage-causing cell death by necrosis as the production of free radical elevated. The toxicity of ASP could be to the metabolites of the methanol which is one of ASP metabolites. Methanol is oxidized to formaldehyde followed by the formation of formate (Parthasarathy, Subramanian, Boder, \& Discher, 2006). Methanol caused mitochondrial injury and elevated microsomal proliferation as the results of the overproduction of free radicals (Humphries, Pretorius, \& Naude', H., 2008).

In the ultrastructure of the ASP group, the cytoplasm of neurons showed vacuolization and reduced mitochondria with indistinct cristae. Disintegration junction capillary wall between the capillary wall and astrocytic perivascular edema with the appearance of more vacuoles and vesiculated RER were observed, whereas sections obtained from rats of ASP with LC showed significant improvement of the ASP produced changes but did not return as in control animals.

LC with ASP caused a significant decline in the levels of MPO, XO, and cytokines and, additionally, the elevation in the activities of GPx, CAT, and SOD of rat brain. Moreover, the SOD/CAT system increase as the result of LC on ASP-treated rats. The ameliorative mechanisms of LC could be by preventing free radical production, mitochondrial dysfunction, and inflammation besides inhibits COX-2 and regulate PGE2. LC decreased cytokine production from epithelial cells and macrophages by a mechanism involving could be by increasing intracellular GSH and thiol levels. Treatment of the rats with LC and ASP resulted in the significant elevation in GSH level and reduced the OX level that could be due to the free radical scavenging properties of LC. All of these observations confirm the view that $\mathrm{LC}$ attenuates the degree of inflammation and oxidative stress caused by ASP administration in rats.

Recently, in our laboratory, LC was found to be a highly potent antioxidant that could inhibit free radical generation in the kidneys and liver of rats (Hamza et al., 2018). It has been showed that it inhibits MPO and XO and prevents apoptotic cell death induced by oxidative stress as well as improved the antioxidant enzymes. Previously, propionic LC $(250 \mathrm{mg} / \mathrm{kg}$; i.p.) decreased the nephrotoxic effects of cisplatin, which increased the lipid peroxidation (LPO) and nitric oxide levels while reducing GSH concentration of rat kidney tissues (Aleisa et al., 2007). Also, LC (100 mg/kg, i.p.) protected the gastric mucosa from ischemia-reperfusion injury by raising the tissue CAT activity and decreasing the LPO level (Derin, Izgut-Uysal, Agac, \& Aliciguzel, 2004).

Also, LC can decrease the inflammatory mediators TNF- $\alpha$ and IL- 6 , and these observations were in parallel with the results of Haghighatdoost, Jabbari, and Hariri (2019). These findings are the same as previous results which confirm LC reduced IL- $1 \beta$, IL- 6 , and TNF- $\alpha$ in the serum and pancreas tissue of diabetic rats (MaSoUMI-ardakaNI, FallaH, \& SHaHoUzeHI, B., 2019). LC decreased TNF- $\alpha$ and IL- 6 by reducing lipid toxicity and improvement of anti-oxidant states; therefore, it reduces pro-inflammatory cytokines and inflammation in the brain tissue of rats that are affected by ASP. LC accelerates acetylcholine production (Di Stefano, Di Lionardo, Galosi, Truini, \& Cruccu, 2019). LC has many neurological effects including neurotrophic factors and multi-neurotransmitter synaptic transmission (Ferreira \& McKenna, 2017).

\section{Conclusion}

ASP induced toxicity in the brain of rats. Neuroameliorative properties of LC may be related to its ability to increase the endogenous antioxidant and neurotransmitters and improve the brain markers as well as decreasing the oxidative stress and inflammatory effects. The enhancement of the biochemical condition was parallel with the improvement of the cellular structure. Therefore, we need to pubicly raise awareness regarding the toxic effects of ASP on brain tissue. Additionally, it could be recommended that using ASP should be restricted or it can be used with exogenous antioxidants. 


\section{Authors' contributions}

RZH suggesting, planning, and designing the study, RAA and NSE performed data analysis, and manuscript writing and editing. The authors read and approved the final manuscript.

\section{Funding}

Not applicable.

\section{Availability of data and materials}

Data will not be shared, only by request from the corresponding author.

\section{Ethics approval and consent to participate}

The rats for the study were humanely handled by the Ethics and Regulation guiding the use of research animals as approved by the University. The study protocol was approved by the Animal Welfare Act and the Guide for the Care and the Use of Laboratory Animals established by Zagazig University, Zagazig, Egypt. Animal experiments received approval from the Ethical Committee (No. P22/2/2013)

\section{Consent for publication}

Not applicable.

\section{Competing interests}

The authors declare that they have no competing interests.

\section{Author details}

${ }^{1}$ Biology Department, Faculty of Science, Taif University, Taif 888, Saudi Arabia. ${ }^{2}$ Zoology Department, Faculty of Science, Zagazig University, Zagazig 44519, Egypt. ${ }^{3}$ Zoology Department, Faculty of Science, Suez Canal University, Ismailia 41522, Egypt.

Received: 2 November 2019 Accepted: 2 April 2020

Published online: 29 May 2020

\section{References}

Abdallah, I. Z. A. (2002). Physiological changes induced by long-term administration of saccharin compared with aspartame to male albino rats. Egyptian Journal of Hospital Medicine, 8, 70-81.

Abdel-Salam, G. M., Abdel-Hamid, M. S., Issa, M., Magdy, A., El-Kotoury, A., \& Amr, K. (2012). Expanding the phenotypic and mutational spectrum in microcephalic osteodysplastic primordial dwarfism type I. American Journal of Medical Genetics - Part A, 158A, 1455-1461.

Abhilash, M., Paul, M. V., Varghese, M. V., \& Nair, R. H. (2011). Effect of long term intake of aspartame on antioxidant defense status in the liver. Food and Chemical Toxicology, 49, 1203-1207.

Akyol, O., Zoroglu, S., Armutcu, F., Sahin, S., \& Gurel, A. (2004). Nitric oxide as a physiopathological factor in neuropsychiatric disorders. Vivo, 18(3), 377-390.

AL-Awady, H. G., \& Hassan, R. S. (2016). Effects of aspartame on dopamine concentration in rats brain. Euphrates Journal of Agriculture Science, 3, 1-8.

Aleisa, A. M., Al-Majed, A. A., Al-Yahya, A. A., Al-Rejaie, S. S., Bakheet, S. A., AlShabanah, O. A., \& Sayed-Ahmed, M. M. (2007). Reversal of cisplatin-induced carnitine deficiency and energy starvation by propionyl-L-carnitine in rat kidney tissues. Clinical Experimental Pharmacology and Physiology, 34, $1252-$ 1259.

Alkafafy, M. E. S., Ibrahim, Z. S., Ahmed, M. M., \& El-Shazly, S. A. (2015). Impact of aspartame and saccharin on the rat liver: Biochemical, molecular, and histological approach. International Journal of Immunopathology and Pharmacology, 28(2), 247-255.

Allen, S. J., Watson, J. J., Shoemark, D. K., Barua, N. U., \& Patel, N. K. (2013). GDNF, N.G.F and BDNF as therapeutic options for neurodegeneration. Pharmacology and Therapeutics, 138, 155-175.

Ashok, I., \& Sheeladevi, R. (2014). Biochemical responses and mitochondrial mediated activation of apoptosis on long-term effect of aspartame in rat brain. Redox Biology, 2, 820-831

Ashok, I., Sheeladevi, R., \& Wankhar, D. (2015). Acute effect of aspartame-induced oxidative stress in Wistar albino rat brain. Journal of Biomedical Research, 29(5), 390-396.

Ates, O., Cayli, S., Altinoz, E., Gurses, I., Yucel, N., Sener, M., ... Yologlu, S. (2007). Neuroprotection by resveratrol against traumatic brain injury in rats. Molecular and Cellular Biochemistry, 294, 137-144.
Bayraktar, N., Paşaoğlu, H., Paşaoğlu, A., Kaymaz, M., Biberoğlu, G., \& Kulaksizoğlu, S. (2008). The relationship between carnitine levels and lipid peroxidation in glial brain tumors. Turkish Journal of Medical Science, 38, 293-299.

Beutler, E., Olga, D., \& Kelly, M. (1963). Improved method for determination of blood glutathione. From the Department of Medicine, City of Hope Medical Centre. Journal of Laboratory and Clinical Medicine, 61, 882-888.

Blaylock, R. L. (2002). Aspartame, monosodium glutamate and other excitotoxins and the hypothalamus. Journal of the Florida Medical Association, 83, 335-341.

Butterfield, D. A., \& Stadtman, E. R. (1997). Protein oxidation processes in aging brain. Advances in Cell Aging and Gerontology, 2, 161.

Cayir, K., Karadeniz, A., Yildirim, A., Kalkan, Y., Karakoc, A., Keles, M., \& Tekin, S. B. (2009). Protective effect of $L$-carnitine against cisplatin-induced liver and kidney oxidant injury in rats. Central European Journal of Medicine, 4, 184-191.

Cetinkaya, A., Bulbuloglu, E., Kantarceken, B., Ciralik, H., Kurutas, E. B., Buyukbese, M. A., \& Gumusalan, Y. (2006). Effects of L-carnitine on oxidant/antioxidant status in acetic acid-induced colitis. Digestive Diseases and Sciences, 51, 488-494.

Chang, J. R., \& Xu, D. Q. (2006). Effects of formaldehyde on the activity of superoxide dismutase and glutathione peroxidase and the concentration of malondialdehyde. Wei Sheng Yan Jiu, 35(5), 653-655.

Choudhary, A. K., \& Devi, R. S. (2015). Longer period of oral administration of aspartame on cytokine response in Wistar albino rats. Endocrinología y Nutrición, 62(3), 114-122.

Ciarlone, A. E. (1978). Further modification of a fluorometric method for analyzing brain amines. Microchemical Journal, 23, 9-12.

Derin, N., Izgut-Uysal, V.N., Agac, A., Aliciguzel, Y., \& Demir ,N. (2004). L-carnitine protects gastric mucosa by decreasing ischemia-reperfusion induced lipid peroxidation. Journal of Physiology and Pharmacology, 55, 595-606.

Di Stefano, G., Di Lionardo, A., Galosi, E., Truini, A., \& Cruccu, G. (2019). Acetyl-Lcarnitine in painful peripheral neuropathy: a systematic review. Journal of Pain Research, 12, 1341

Elshazly, S. A., Ahmed, M. M., Hassan, H. E., \& Ibrahim, Z. S. (2012). Protective effect of $\mathrm{L}$-carnitine against $\mathrm{\gamma}$-rays irradiation-induced tissue damage in mice. American journal of Biochemical and Molecular Biology, 2, 120-132.

Engblom, D., Monica, E. K., Dahlstrand, S. S. A., \& Blomqvist, P. J. (2002). Prostaglandins as inflammatory messengers across the blood-brain barrier. The Journal of Molecular Medicine, 80, 5-15.

Ethell, I. M., \& Pasquale, E. B. (2005). Molecular mechanisms of dendritic spine development and remodeling. Progress in Neurobiology, 75, 161-205.

Ferreira, G. C., \& McKenna, M. C. (2017). L-Carnitine and acetyl-L-carnitine roles and neuroprotection in developing brain. Neurochemical Research., 42(6), 1661-1675.

Gabe, M. Techniques Histologiques. Massie e Cie 1968; Paris, pp. 1113

Graham, S. H., \& Hickey, R. W. (2003). Cyclooxygenases in central nervous system diseases: a special role for cyclooxygenase 2 in neuronal cell death. Archives of Neurology, 60, 628-630.

Gulec, M., Gurel, A., \& Armutcu, F. (2006). Vitamin E protects against oxidative damage caused by formaldehyde in the liver and plasma of rats. Molecular of Cell Biochemistry, 290(1-2), 61-67.

Hafeman, D. G., Sunde, R. A., \& Hoekstra, W. G. (1974). Effect of dietary selenium on erythrocyte and liver glutathione peroxidase in the rat. Journal of Nutrition, 104, 580-587.

Haghighatdoost, F., Jabbari, M., \& Hariri, M. (2019). The effect of L-carnitine on inflammatory mediators: a systematic review and meta-analysis of randomized clinical trials. European Journal of Clinical Pharmacology, 26, 1-10.

Hamza, R., Al-Eisa, R. A., Mehana, A. E., \& El-Shenawy, N. S. (2018). The influence of $\mathrm{L}$-carnitine on aspartame toxicity in kidney of male rats. International Journal of Pharmacology, 14, 1118-1127.

$\mathrm{Hu}, \mathrm{M}$. L. (1994). Measurement of protein thiol groups and glutathione in plasma. Methods in Enzymology, 233, 380-385.

Humphries, P., Pretorius, E., \& Naudé, H. (2008). Review: Direct and indirect cellular effects of aspartame on the brain. European Journal of Clinical Nutrition, 62, 451-462.

lyyaswamy, A., \& Rathinasamy, S. (2012). Effect of chronic exposure to aspartame on oxidative stress in brain discrete regions of albino rats. Journal of Biosciences, 37, 1-10.

Juliet, P. A., Joyee, A. G., Jayaraman, G., Mohankumar, M. N., \& Panneerselvam, C. (2005). Effect of $L$-carnitine on nucleic acid status of aged rat brain. Experimental of Neurology, 191, 33-40.

Kanemitsu, H., Tamura, A., Kirino, T., Oka, H., Sano, K., \& Iwamoto, T. (1989). Allopurinol inhibits uric acid accumulation in the rat brain following focal cerebral ischemia. Brain Research, 499, 367-370. 
Kir, H. M., Şahin, D., Öztaş, B., Musul, M., \& Kuskay, S. (2013). Effects of single-dose neuropeptide $Y$ on levels of hippocampal BDNF, MDA, GSH, and $\mathrm{NO}$ in a rat model of a pentylenetetrazole-induced epileptic seizure. Bosnian Journal of Basic Medical Sciences, 13(4), 242

Lu, J., Vallabhaneni, H., Yin, J., \& Liu, Y. (2013). Deletion of the major peroxiredoxin Tsa1 alters telomere length homeostasis. Aging Cell, 12(4), 635-644.

Magnotti, R. A., Eberly, J. P., \& McConnell, R. S. (1988). Field measurement of plasma and erythrocyte cholinesterases. Clinica Chimica Acta, 176, 315-332.

Marklund, S., \& Marklund, G. (1974). (1974). Involvement of the superoxide anion radical in the autoxidation of pyrogallol and a convenient assay for superoxide dismutase. European Journal of Biochemistry, 47, 469-474.

MaSoUMI-ardakaNI, Y., FallaH, H., \& SHaHoUzeHI, B. (2019). Carnitine effects on serum and pancreas inflammatory response in diabetic rats. Ukrainian Biochemical Journal, 91(6), 59-66.

Minghetti, L. (2004). Cyclooxygenase-2 (COX-2) in inflammatory and degenerative brain diseases. Journal of Neuropathology \& Experimental Neurology, 63(9), 901-910.

Mourad, I. M., \& Noor, N. A. (2011). Aspartame (a widely used artificial sweetener) and oxidative stress in the rat brain. Journal of Pharmaceutical and Biomedical Sciences, 2(1), 4-10

Nosti-Palacios, R., Gómez-Garduño, J., Molina-Ortiz, D., Calzada-León, R., DoradoGonzález, V. M., \& Vences-Mejlá, A. (2014). Aspartame administration and insulin treatment altered brain levels of CYP2E1 and CYP3A2 in streptozotocin-induced diabetic rats. International Journal of Toxicology, 33(4), 325-331.

Nweze, C. C., Mustapha, A. A., \& Olose, M. (2015). Aspartame food additive and its biochemical implication: A review. Food Science and Quality Management, 36, $16-22$.

Parthasarathy, R., Subramanian, S., Boder, E. T., \& Discher, D. E. (2006). Posttranslational regulation of expression and confirmation of an immunoglobulin domain in yeast surface display. Biotechnology and Bioengineering, 93(1), 159-168.

Prajda, N., \& Weber, G. (1975). Malignant transformation-linked imbalance: decreased xanthine oxidase activity in hepatomas. FEBS Letters, 59, 245-249.

Prakash, A., Jaspreet Kaur Kalra, J. K., \& Kumar, A. (2015). Neuroprotective effect of $\mathrm{N}$-acetyl cysteine against streptozotocin-induced memory dysfunction and oxidative damage in rats. Journal of Basic Clinical Physiology and Pharmacology, 26(1), 13-23.

Ruszkiewicz, J., \& Albrecht, J. (2015). Changes in the mitochondrial antioxidant systems in neurodegenerative diseases and acute brain disorders. Neurochemistry International, 88, 66-72.

Rycerz, K., \& Jaworska-Adamu, J. (2013). Effects of aspartame metabolites on astrocytes and neurons. Folia Neuropathologica, 51(1), 10-17.

Schultz, L. B., Chehab, N. H., Malikzay, A., \& Halazonetis, T. D. (2000). p53 binding protein 1 (53BP1) is an early participant in the cellular response to DNA double-strand breaks. Journal of Cell Biology, 151(7), 1381-1390.

Siktar, E., Ekinci, D., Beydemir, S., Gulcin, I., \& Gunay, M. (2011). Protective role of Lcarnitine supplementation against exhaustive exercise-induced oxidative stress in rats. European Journal of Pharmacology, 668, 407-413.

Soffritti, M., Belpoggi, F., Tibaldi, E., Esposti, D. D., \& Lauriola, M. (2007). Lifespan exposure to low doses of aspartame beginning during prenatal life increases cancer effects in rats. Environmental Health Perspectives, 115(9), 1293-1297.

Solaroglu, I., Okutan, O., Kaptanoglu, E., Beskonakli, E., \& Kilinc, K. (2005). Increased xanthine oxidase activity after traumatic brain injury in rats. Journal of Clinical Neuroscience, 12, 273-275.

Strauss, E. J., Weil, W. M., Jordan, C., \& Paksima, N. (2008). A prospective, randomized, controlled trial of 2-octyl cyanoacrylate versus suture repair for nail bed injuries. The Journal of Hand Surgery, 33(2), 250-253.

Suzuki, K. T., Tanaka, Y., \& Kawamura, R. (1983). Properties of metallothionein induced by zinc, copper, and cadmium in the frog, Xenopus laevis. Comparative Biochemistry \& Physiology C, 75(1), 33-37.

Tsakiris, S., Giannoulia-Karantana, A., Simintzi, I., \& Schulpis, K. H. (2006). The effect of aspartame metabolites on human erythrocyte membrane acetylcholinesterase activity. Pharmacological Research, 53, 1-5.

Ueno, Y., Koike, M., Shimada, Y., Shimura, H., Hira, K., Tanaka, R., ... Urabe, T. (2015). L-carnitine enhances axonal plasticity and improves white-matter lesions after chronic hypoperfusion in rat brain. Journal of Cerebral Blood Flow \& Metabolism, 35, 382-391.

Weakley, B., \& Beginner, S. (1981). Handbook in Biological Transmission Electron Microscopy, (Second ed., ). London: Churchill Livingstone.
Whitehouse, C. R., Boullata, J., \& McCauley, L. A. (2008). The potential toxicity of artificial sweeteners. Journal of Basic Clinical Physiology and Pharmacology, 26(1), 6792-6855.

Yildirim, S., Yildirim, A., Dane, S., Aliyev, E., \& Yigitoglu, R. (2013). Dose-dependent protective effect of L-carnitine on oxidative stress in the livers of hyperthyroid rats. The Eurasian Journal of Medicine, 45(1), 1.

\section{Publisher's Note}

Springer Nature remains neutral with regard to jurisdictional claims in published maps and institutional affiliations.

\section{Submit your manuscript to a SpringerOpen ${ }^{\circ}$ journal and benefit from:}

- Convenient online submission

- Rigorous peer review

- Open access: articles freely available online

- High visibility within the field

- Retaining the copyright to your article

Submit your next manuscript at $\boldsymbol{\nabla}$ springeropen.com 